\title{
Observação e experimentação da Tecnologia 40 no projeto de arquitetura
}

\author{
Observation and experimentation of 4D Technology in architectural design
}

\author{
> Marcella Guerra Matos \\ LCAD / UFBA, Brasil. PGCOC / UFRJ, Brasil. \\ guerra.marcella@gmail.com
}

\begin{abstract}
This paper presents an experimentation of the use of $4 \mathrm{D}$ technology in order to generate a simulation. An approach will be made about this technology, as well as its evolutionary process, and how the graphical representation is changing and used in various applications. It will be shown the advantages fourth dimension can bring to the realization of architectural projects, as well as some advice for the process will be really efficient.
\end{abstract}

Keywords: 4D; BIM (Building Information Modelling); Construction manager; Simulation

\section{Introdução}

O modo de representação do projeto passou por diversas mudanças ao longo da história sempre impulsionadas pelos avanços tecnológicos. Hoje vive-se numa era em que esses avanços ocorrem num ritmo muito mais intenso do que outro jamais visto. Hoje ultrapassou-se o conceito da mera representação, com o surgimento do Building Information Modeling (BIM). A representação não é mais o fim, e sim, consequência.

A tecnologia 4D chega como importante apoio ao BIM. Viabilizando aplicaçóes na construção e sua simulação, possibilitando que o modelo BIM seja utilizado em outras etapas do ciclo de vida da edificação. As aplicaçóes 4D associam o tempo ao modelo geométrico, possibilitando dentre outras coisas, simulação da sua evolução.

Neste artigo é apresentado um experimento envolvendo a tecnologia 4D, o método utilizado para desenvolvê-la e o resultado obtido: a simulação da construção dos principais elementos construtivos durante um determinado tempo. Sáo expostas as dificuldades encontradas no desenvolvimento da aplicação e observaçóes para otimizaçáo do processo.

"O planejamento da construção que utiliza a simulação 4D permite que o processo seja visualizado em qualquer momento da linha de tempo. Esta forma de simulação gráfica facilita a detecção de possíveis problemas operacionais da obra e possibilita um melhor planejamento de localização de equipamentos, conflitos de espaços, problemas de segurança do trabalho, espaço de circulação dos trabalhadores, ou seja, é uma forma de se ter o controle do dia-a-dia da obra e prever problemas futuros" (EASTMAN, TEICHOLZ, SACKS, LISTON, 2011, p. 24).
Ainda com o 4D é possível a visualização de elementos temporários como: escoramentos, andaimes, guindastes etc.

Os modelos 4D começaram a ser desenvolvidos no final dos anos 80 por grandes corporaçôes que visavam diminuir a incongruência entre prazo planejado e prazo realizado. "O 4D já foi manual. Muitos construtores já utilizaram lápis e desenhos com cores diferentes para demonstrar a progressão de uma obra no tempo." (EASTMAN, TEICHOLZ, SACKS, LISTON, 2011, p. 286).

Após o advento do CAD esses processos começaram a ser automatizados, começando a existir a possibilidade de melhor controle de recursos, como layers, que podem ser desligados e ligados com o objetivo de demonstrar determinado momento do projeto. Em meados dos anos 90 os modelos 4D foram linkados com a geometria 3D. O BIM trouxe mais credibilidade ao processo, pois com esse tipo de sistema tem-se o controle dos elementos 3D da obra.

\section{Estudo de casos}

\section{Hut-600}

O projeto do auditório da Helsinki University of Technology Auditorium Hall 600 ou HUT-600, assim chamado por sua capacidade de 600 pessoas, foi um dos pioneiros no uso do PM4D (Product Model and Fourth Dimension). Ele foi desenvolvido por uma equipe de pesquisadores, cujo método de projeto empregava simulaçóes, cujos resultados influenciavam na etapa conceitual do projeto. Este foi um caso pioneiro também no uso do IFC (Industry Foundation Classes), porque a comunicação entre diferentes disciplinas era um 
ponto principal. Para se ter uma ideia de quáo inovador foi este projeto, a equipe pôde desenvolver três diferentes alternativas e selecionar aquela mais eficiente, em termos de energia, economia e agilidade de obra. A equipe se concentrou com profundidade nos estudos de ciclo de vida da edificação por acelerarem a etapa conceitual. Os benefícios do 4D frente a projetos desenvolvidos de forma tradicional estão ilustrado na Quadro 1.

\section{Quadro 1. Projeto tradicional x Projeto Hut-600.}

\begin{tabular}{|c|c|c|c|}
\hline & $\begin{array}{l}\text { Projeto } \\
\text { tradicional }\end{array}$ & Hut-600 & Beneficios \\
\hline $\begin{array}{l}\text { Coordenação } \\
\text { de Projeto }\end{array}$ & $\begin{array}{l}\text { Os projetos } \\
\text { complemen-tares } \\
\text { são desenvolvi- } \\
\text { dos quando } \\
\text { o projeto de } \\
\text { arquitetura já está } \\
\text { finalizado }\end{array}$ & $\begin{array}{l}\text { Consultores e } \\
\text { gerentes de obra } \\
\text { são consultados } \\
\text { durante a fase } \\
\text { conceitual de } \\
\text { projeto }\end{array}$ & $\begin{array}{l}\text { Fomenta a } \\
\text { colaboração } \\
\text { interdisciplinar } \\
\text { desde cedo } \\
\text { e a troca de } \\
\text { experiências }\end{array}$ \\
\hline $\begin{array}{l}\text { Compartilha- } \\
\text { mento de } \\
\text { informaçôes }\end{array}$ & $\begin{array}{l}\text { Projeto no papel } \\
\text { ou digital sem } \\
\text { interoperabi- } \\
\text { lidade, } \\
\text { transmitidos por } \\
\text { e-mail ou correio }\end{array}$ & $\begin{array}{l}\text { Modelos } \\
\text { geometricos, com } \\
\text { interoperabili- } \\
\text { dade, padróes IFC } \\
\text { e banco de dados } \\
\text { do projeto }\end{array}$ & $\begin{array}{l}\text { Minimiza a } \\
\text { redundância de } \\
\text { dados, melhora } \\
\text { a precisão e } \\
\text { qualidade, } \\
\text { possibilita a } \\
\text { geração de } \\
\text { alternativas } \\
\end{array}$ \\
\hline $\begin{array}{l}\text { Projeto/ } \\
\text { Qualidade da } \\
\text { obra }\end{array}$ & $\begin{array}{l}\text { Projeto } \\
\text { desenvolvido } \\
\text { por exigências, } \\
\text { experiência } \\
\text { pessoal, e } \\
\text { suposiçốes }\end{array}$ & $\begin{array}{l}\text { Análise dinâmica, } \\
\text { simulação } \\
\text { no software } \\
\text { e produção } \\
\text { automatizada da } \\
\text { documen-taçáo }\end{array}$ & $\begin{array}{l}\text { Melhora a } \\
\text { precisão do } \\
\text { projeto, transfere } \\
\text { os esforços da } \\
\text { equipe de projeto, } \\
\text { assim sobra } \\
\text { mais tempo para } \\
\text { desenhos de } \\
\text { detalhe }\end{array}$ \\
\hline Colaboração & $\begin{array}{l}\text { Colaboração } \\
\text { ocorre em } \\
\text { reuniōes com } \\
\text { desenhos } \\
\text { estáticos }\end{array}$ & $\begin{array}{l}\text { A equipe de } \\
\text { projeto trabalha } \\
\text { com um modelo } \\
\text { "ao vivo" que } \\
\text { possibilita várias } \\
\text { visualizaçóes } \\
\text { durante a reunião }\end{array}$ & $\begin{array}{l}\text { Projeto } \\
\text { desenvolvido } \\
\text { num ritmo } \\
\text { mais acelerado } \\
\text { e geração rápida } \\
\text { de soluçóes de } \\
\text { projeto }\end{array}$ \\
\hline
\end{tabular}

De acordo com os participantes do projeto, a documentação representa de 60 a $70 \%$ do tempo num projeto desenvolvido na maneira tradicional. Os projetistas do Hut-600 disseram que economizaram $50 \%$ de tempo na fase de documentação. Esta agilidade se deu principalmente por disporem de bibliotecas e catálogos, propriedades paramétricas e outras ferramentas automatizadas, num nível bem avançado. Consequentemente, eles passaram mais tempo se dedicando à construtibilidade do projeto, gerando alternativas e conduzindo análises do ciclo de vida da edificação.

\section{Crusell Bridge}

No caso da ponte Crusell, uma ponte estaiada em Helsinki, o 4D foi utilizado de forma diária. A equipe gerava uma animação com as atividades do dia, o que esclarecia a sequência de execução para toda a equipe.

"O modelo permitia à equipe desenvolver um plano de trabalho mais detalhado e apurado do que normalmente conseguiam, por providenciar uma informaçáo espacial mais apurada e dar uma maior precisão ao quantitativo de materiais necessitados. Providenciou uma fácil e rápida extração precisa da tabela de quantitativos de materiais do modelo no Tekla Structures, o qual ajudou a reduzir a necessidade por cortes de excesso de materiais e garantir que apenas os materiais necessários fossem solicitados aos fornecedores." (EASTMAN, TEICHOLZ, SACKS, LISTON, 2011, p. 506).

\section{Experimento}

O experimento realizado teve como objeto a reforma e ampliação do Teatro Castro Alves (TCA), em Salvador, Bahia. O Novo TCA, além de receber melhorias nas suas salas existentes, será ampliado com a criação de uma sala sinfônica e um laboratório para montagens cenográficas, e ainda, uma garagem para 300 vagas. O projeto, de autoria do Estúdio América, baseado em São Paulo, foi selecionado num concurso público nacional. Por motivo de captação de recursos decidiu-se que a obra será realizada em etapas.

O objetivo dessa experimentação 4D foi a simulação da construção da primeira etapa da obra que consiste na reforma da Concha Acústica, camarins, e a construção do edifício garagem. Para a construção desse novo edifício, será necessário um grande corte no terreno. A solução mais indicada pela equipe de geotecnia foi a construçáo de uma cortina atirantada reforçada com estacas-raíz. Entretanto, essa etapa da contenção foi excluída da simulação 4D, sendo apenas representada a construção do edifício em si, com seus principais elementos estruturais (lajes, vigas e pilares). Por se tratar de um primeiro experimento a simplificação da simulaçáo foi necessária.

O uso do 4D neste projeto é vantajoso pois a área de obras apresenta algumas dificuldades, como o acesso para entrada e saída de materiais. $\mathrm{O}$ único acesso de veículos ao canteiro se dá pela Ladeira da Fonte, mais conhecida como ladeira da Concha, bastante estreita e com forte declive. $\mathrm{O} 4 \mathrm{D}$ possibilita uma melhor racionalização de como os materiais pudessem chegar e sair da obra, assim como a posição das construçóes de apoio no canteiro.

\section{Metodologia}

Para desenvolver o experimento foram utilizadas três ferramentas: o Revit Architecture (Autodesk), o MS Project (Microsoft) e o Naviswork (Autodesk). Para desenvolver uma aplicação 4D satisfatória e eficiente, foi necessário trabalhar com os três programas com as seguintes características:

- Programa para modelagem geométrica: de preferência BIM, para assegurar um maior controle dos objetos e agilidade caso alguma mudança ocorra no projeto;

- Programa para planejamento: onde se possa estabelecer o planejamento de tarefas numa linha de tempo (cronograma). É essencial que o usuário conheça de fato as etapas de obra, pois os programas nem sempre são específicos para a área de construção;

- Programa de simulação 4D: esse programa tem o papel de vincular o modelo geométrico com a tabela de planejamento de tarefas, resultando numa animação que simula a construçáo no tempo estabelecido. Alguns programas 
$4 \mathrm{D}$ possuem o recurso de "clash detection" que permite identificar os conflitos entre elementos construtivos, o que auxilia no gerenciamento da obra.

\section{Modelagem}

O projeto do Novo TCA não foi desenvolvido em BIM, então consumiu-se um tempo no começo do processo para a geraçáo do modelo geométrico (Revit). Idealmente, os projetos que serão simulados em $4 \mathrm{D}$ são desenvolvidos com BIM desde o seu início; isso é importante para o sucesso do processo, principalmente quando há mudanças no projeto.

O início da modelagem se deu pela geração da superfície do terreno. No Revit este processo é prático quando o terreno está no formato $d w g$ e já possui os pontos com suas cotas definidas, como foi o caso. Após a criação do terreno a modelagem se concentrou nas áreas de escavaçóes e terraplenagem.

A criação das lajes e pilares teve que seguir uma disciplina rigorosa, pois as propriedades dos elementos precisavam estar bem definidas, para serem manipuladas e selecionadas pelo programa 4D. Todos os elementos precisavam estar com suas propriedades corretamente ajustadas para o seu devido pavimento.

Após a finalização da modelagem, utilizou-se um plug in para exportar o modelo geometrico para algum programa 4D. Com a instalação do Naviswork no sistema, o Revit automaticamente cria o botão External Tools. É com esse comando que é exportado o modelo. Inicialmente é criado um arquivo cachê, de extensão nwc, que após ser aberto e salvo no Naviswork se transforma de fato num arquivo $n w f$ definitivo.

\section{Planejamento}

O planejamento das tarefas de obra foi feito no MS Project, um conhecido programa da Microsoft muito utilizado para se fazer cronogramas e que possui vários recursos relacionados à gestão de projetos.

Foi importante nesta etapa a listagem das tarefas e sua ordem no tempo; algum erro nesta fase comprometeria toda a simulação posterior. É preciso um conhecimento prévio da sequência de tarefas numa obra de construção civil.

A figura acima representa um gráfico de Gantt. Este gráfico ilustra, através de linhas horizontais, o decorrer de uma determinada tarefa no tempo. À esquerda estão as descriçóes das tarefas, e à direita sua

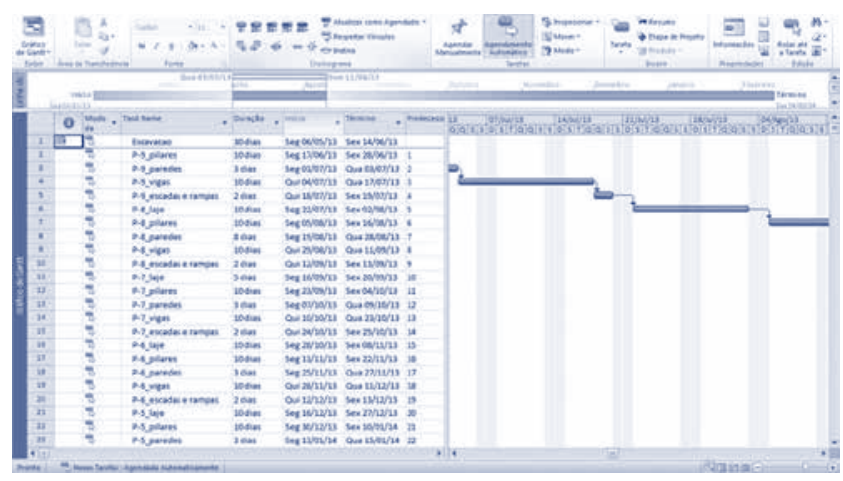

Figura 1: Tabela de Gantt.Fonte: Matos, 2014. posição no calendário de planejamento. Esse é um gráfico utilizado em várias áreas de gestão, não só a da construção civil. É interessante estabelecer a conexão entre tarefas, pois algumas dependem da conclusão de outras para iniciarem, o programa permite fazer isso. Assim, quando há alteração na data de uma determinada tarefa, as outras conseguintes mudam também automaticamente.

\section{Simulação}

Ao importar o modelo no Naviswork todos os seus elementos tridimensionais são organizados de maneira automática por pavimentos. Para isso funcionar eles precisam ser modelados corretamente, como explicitados anteriormente. O Naviswork possibilita uma boa visualização do modelo, que pode ser girado, e possui a opção de vê-lo em perspectiva, não apenas na forma isométrica. Porém o modelo geométrico não pode aí ser alterado. Qualquer alteração na sua geometria precisa ser feita no programa de modelagem geométrica.

Após a importação do modelo, importa-se a tabela de tarefas do MS Project. É possível criar as tarefas de modo simplificado dentro do próprio Naviswork, porém esta náo é a maneira mais indicada quando se está trabalhando com um projeto de maior complexidade. Neste caso é melhor desenvolver o cronograma num programa específico.

O Naviswork trabalha com três janelas: uma mostra o modelo, acima, e as duas inferiores mostram as tarefas com seus respectivos tempos de duração à esquerda, como num gráfico de Gantt. Ainda nessa janela inferior se encontram as guias:

- Guia Tasks: onde ficam localizadas as tarefas da construçáo;

- Guia Data Sources: guia dedicada às planilhas e dados importados;

- Guia Configure: define tipos, parâmetros e visibilidade das tarefas;

- Guia Simulate: faz a simulação de acordo com os parâmetros de planejamento;

Após definidas as tarefas e com o modelo já importado, a próxima etapa é adicionar os sets, que são muito importantes, pois sem eles náo há como gerar a animação simulando a construção dos elementos. Para selecionar os elementos e estabelecer uma tarefa a eles adicionando o set correspondente, utiliza-se a selection tree que mostra todos os elementos 3D do arquivo organizados por pavimentos.

Com todos os sets definidos é possível gerar uma animação com os comandos da guia simulate.

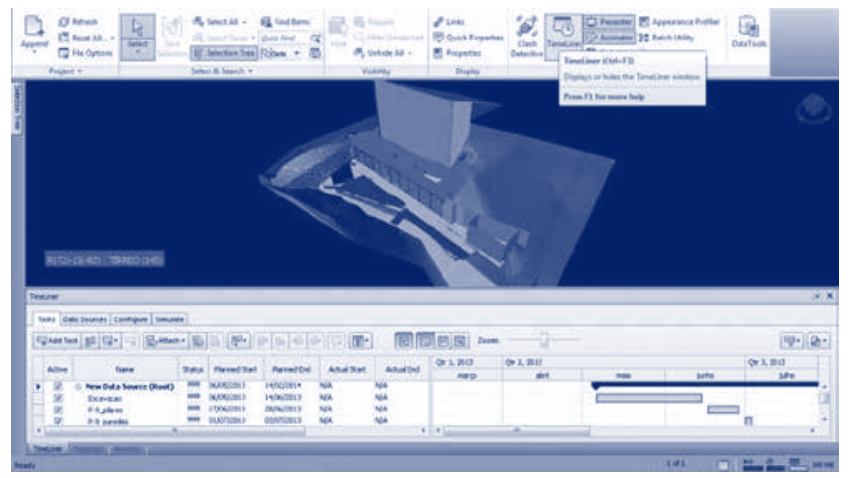

Figura 2: Interface do Naviswork. Fonte: Matos, 2014. 


\section{Análise e Discussão dos Resultados}

A animação serviu como um primeiro teste para experimentar as ferramentas.

O vídeo gerado com a animação, apesar de curto, em torno de 20 segundos, ficou com um tamanho final um tanto grande, cerca de $325.000 \mathrm{~Kb}$. Ajustes podem ser feito nas opçóes de exportação do Naviswork, como alterar o número de quadros por segundo. O número razoável de quadros por segundo é de 10 a $15 \mathrm{fps}$, porém reduzindo o número de quadros a suavidade da reprodução fica comprometida.

A comunicação e visualização dos elementos sendo construídos durante o tempo são reforçadas pelas diferentes cores, que podem ser manipuladas no programa. Quando o elemento começa a ser construído está na cor verde, e quando está finalizado apresenta a cor de sua renderização original.

Os elementos provisórios poderiam ser representados para um estudo da disposiçáo espacial no canteiro de obras, como gruas, guindastes e andaimes.

A modelagem poderia ganhar características de detalhes, por exemplo: a montagem da laje em Steel Deck, demonstrando a aplicação das chapas metálicas e camada de concreto. O Naviswork, no experimento, foi utilizado de maneira muito generalista, como um teste, mas ele poderia ser utilizado para mostrar mais detalhes construtivos da obra. Diversas animaçóes poderiam ser feitas mostrando diferentes detalhes. $\mathrm{O}$ experimento serviu como um teste e confirmou que a simulação era possível e útil ao planejamento da obra.

\section{Considerações Finais}

A simulação nunca será igual à realidade com os seus imprevistos, mas é exatamente isso o que motiva o desenvolvimento de sofisticadas tecnologia de visualização, que está sempre tentando aproximar o mundo digital o mais próximo possível da realidade.

A reprodução da realidade, no entanto, oferece maior segurança, pois é muito mais fácil executar aquilo já foi feito antes, mesmo que virtualmente. $\mathrm{O}$ objetivo disso tudo é minimizar o número de erros de execução, pelo menos aqueles possíveis de previsão.

A simulaçáo também teria um papel importante para comunicar à populaçáo leiga as fases de obra, pois muitas geram transtornos provisórios que náo são muito bem compreendidos pela população.

\section{Referências}

Fischer, M.; Hanniner, R.; Kam, C.; Karjalainen, A.; Laitinen, J. The product model and fourth dimension project. ITcon, v. 8, n. Special Issue IFC - Product models for the AEC arena, p. 137-166, July 2003. Disponível em: http://www.itcon. org/2003/12 p. 139-142.

Eastman, C; Teicholz, P; Sacks, R; Liston, K. BIM Handbook: A Guide to Building Information Modeling for Owners, Managers, Designers, Engineers and Contractors. Second Edition, 2011. p. 24. p. 505-507.

Ruschel, R. C.; Guimarães Filho, A.B. Iniciando em CAD 4D. In: WORKSHOP BRASILEIRO GESTÃO DO PROCESSO DE PROJETOS NA CONSTRUÇÃO DE EDIFÍCIOS, 8., 2008, São Paulo. Anais... São Paulo: Escola Politécnica da USP, 2008. p. 2.
Vandezande, J.; Read, P.; Krygiel, E.; Mastering Autodesk Revit Architecture 2012. 2011. p. 874-880.

Brasiel, M.; Lima, C. Planejamento 4D com Navisworks a partir de um modelo criado no Revit. In: Autodesk University Brasil 2012, São Paulo, 2012. p. 10-17.

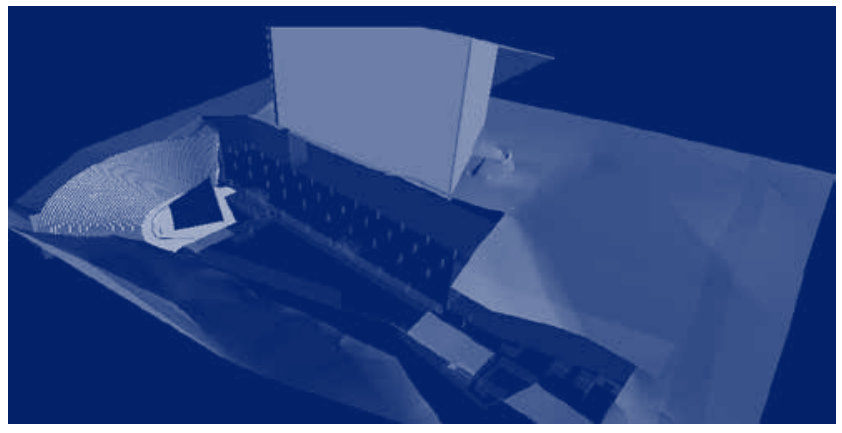

Figura 3: Instantâneos da Simulaçăo (Etapa 1). Fonte: Matos, 2014.

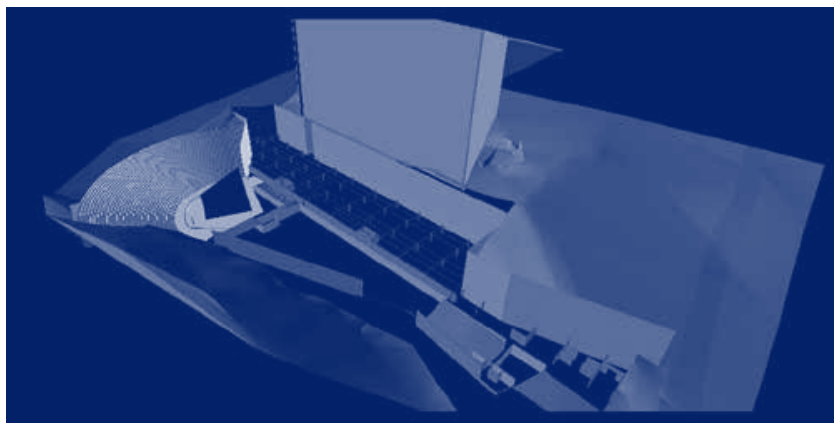

Figura 4: Instantâneos da Simulaçăo (Etapa 2). Fonte: Matos, 2014.

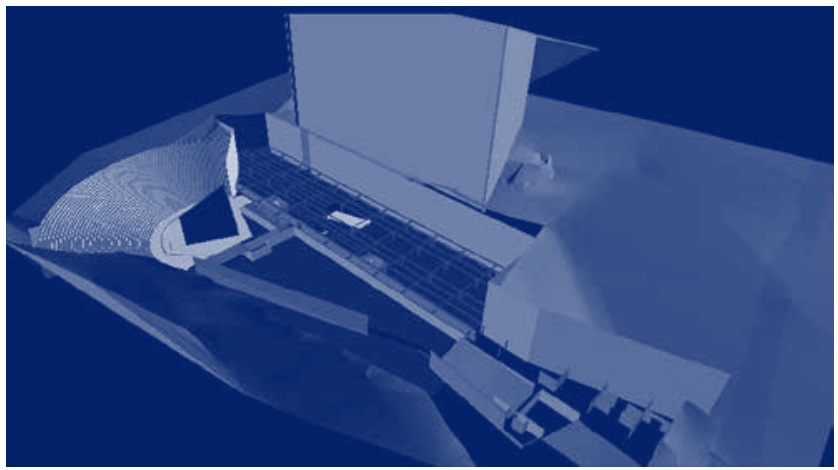

Figura 5: Instantâneos da Simulação (Etapa 3). Fonte: Matos, 2014.

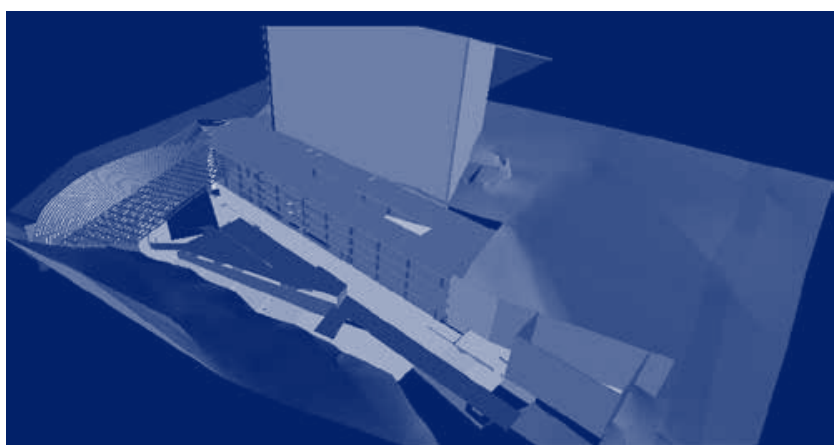

Figura 6: Instantâneos da Simulaçáo (Etapa 4). Fonte: Matos, 2014. 